\title{
SOME ASPECTS CONCERNING THE ATTRIBUTES OF CONDUCTING
}

\author{
Ciucescu Nicoleta, Assistant \\ UNIVERSITY OF BACĂU
}

\section{Abstract:}

The activity of the management has a millennial existence, during it have been realized multiple progresses which have contributed to the developement of the society in its assembly. The evolution of the human society makes possible the progress in the science of conducting. In all kinds of companies, without keeping into account their domain of activity (industry, trading, tourism, agriculture etc.) or their dimensions, it appears the atributes of the conducting. In each organization the attributes of the conducting are present at all hierarchical levels. Each manager disposes on authority, power, responsability; they differ sensibly from a hierarchical level to another.

Each manager have to manifest a sentiment of duty to the achievement of the objectives of the organization, correlated with those of himself.

All managers from an organisation have authority. On one hand, the authority represents that right of the manager to take decisions, by which are allocated the resources and are consumed resources and, on another hand, that right to ask to the personnel the achievement of the objectives of the organization. The authority is a tool of the manager giving him the possibility to command, to ask to someone to do or not to do something, and, finally, to maintain the organization as entity.

It pulls out its roots in the formal position in the frame of the organization and it can be delegated, in the sense that it can be surrended temporary or definitively, totally or partially.

The approach of the authority may be made in a double hypostasis:

- official authority;

- professional authority.

The official authority overtakes the decisional liberty in the sense of the possibility of the implication by the intermedium of the decisions, having as target the finding of some solutions with wich is confronting the organization. It is influenced both by the content of some normative documents, as well as by the decisions with internal organizationa character.

The professional authority refers to the assembly of knowledges, aptitudes and qualities to be possessed by the manager in order to achieve successfully the job he was appointed.

This depends in a series of components as, for example: the accumulated experience in the the activity of management, the training from the professional point of view, conceptual aptitudes - the capacity to assure the strategic orientation of the organization, and the human aptitudes - the capacity to develop human relations, his social and psichological aptitudes etc.

The psichological value of the adopted decisions by the managers from every hierarchic level is confered by the professional authority.

In order to become effective, the authority may be accepted as it is, in the sense that the subalternes have to recognize the right of the conductor to take decisions and to apply them, assuring a good cooperation between subalterns.

In the speciality literature it have been identified three essential types of authority:

$>\quad$ line - of decision on all the essential activities precised in the missions of the organisation. The lines of direct authority constitute the basic organizational structure and define both the hierarchic levels as well the existing relations between them. The decision lines represent, also, the communication and reporting lines in the organization.

$>\quad$ staff - reffers to the technical support, advising, researches and developing - all these sbordinated to the essential activities. 
From this category may be mentioned a series of composing elements, between them may be reminded the personnel management, the financial and logistical parts, the systemic relations, the research, the development, all contributing to the achievement of the mission of the organization.

functional - bent to some specialised objectives and targets which, it may say, are not essential or auxiliary.

The functional authority is delegated to the specialised persons in a certain domain which, usually, endorses methodologies and working procedures for another sectors of activity.

In the most cases, the functional authority is manifesting outside the conventional hierarchies and conventional organizational structures. To exemplify, it may mention those situations in which, the institutions, responding to the guard and extinction of fires, take decisions inside the organization (they accord the working authorisation, go till to apply sanctions for the unobservation the security conditions), even if they are not in the structure of the system. Similarly, are the cases of the sanitary or the institutions responding for the civil defence, working protection etc.

The exercising of the authority is strongly influenced by the combined actions of the following factors:

- the colaborators, when the assigned charges and assigned atributions of the job can not be fulfilled without their implication;

- the subordinates may recognize the right of the manager to take decisions and to apply them;

- the organization itself by its established practices and rules.

The degree of the authority with wich is invested a person is specified in the poste chart. [1]

The authority is a concept strongly bent with that of the power. It is necessary the specification that the authority can not be confounded with the power.

The power is a wider concept expressing the capacity (ability) of the persons and groups to convince or the influence, conception and actions of other persons with which are in working relations.
The power, iteself, is not "good" or "bad". Its influence may be in a positive sense, if it sanctions or limits the lack of efficiency in actions, but, also, in negative sense, if it blocks the actions by different methods manipulating the groups. In other words, the power is the ability to influence the behaviour of others and represents that characteristic of the interpersonal relations having as basis a combination of the authority, native qualities and resources.

The power may be, also, interpreted or understood as that aspiration to the resources of the organization, the pleasure to command, to be listened or to reward others for the benefit of the groups or of the whole organization.

In his book "Power: The Inner Experience", David McClelland defines the need of power as the wish to have an influence on others and is maturing concomitant during:

- involving of other persons in initiated or developed actions;

- giving help or advices to others;

- controlling others;

- actions producing emotions to others;

- preoccupations to the reputation.[2]

According to some studies, having as aim the determination of the human models starting from the men which have obtained power, it were identified two categories, as follows:

- the person eager of power having a series of characteristics (ambitious, agresive, unscrupulous, neurotic, full of inferiority complexes;

- the person considered beneficial, which may be characterized by: high capacity to synthetize and analyse, calm, affable, which influence the others to realize the objectives of the organization, use efficiently the resources and, even, makes anothers to feel theirself stronger.

The american psichologistst John French and Bertram Raven have identified five sources of the power at the level of the organization, exlaining the fact that the power is found in the position occupied in the organization and the resources which he disposes. The sources of power are as follows: the power as award, the coercitive 
power, the legitimate power, the power as reference, the power of the expert.

The power as award represents that capacity to influence the behaviour of the people by the intermediate of the awards, having as aim the obtaining of positive effects and the prevention of those negative. This may be realized by one of the following ways of action: the increase of wages, the promotion on another poste, giving new equipments, according bonuses, the evaluation of the performances, increasing responsabilities, recognition.

By the mean of this capacity, the manager has the force to administrate the positive valences of another persons, perceived as they are.

The coercitive power represents the capacity to sanction, to apply punishments or to determine unpleasant consequences.

In the frame of the organization, those detaining different hierarchical positions exerce their coercitive power by the possibility to reduce the wage, to retrograde, to block the promotion, to distribute unsuitable working charges and may compel by threatening, verbal reprimands going till dissmissing etc.

This source of power depends on the fear to be sanctioned when you do not respect the rules, the directives and the politics of the organization. The management of the organization is accomplished in this situation by generating fear and tensions.

The legitimacy is another source of power. The legitimate power is confered by the position, the poste or the role had in the frame of the organization and represents the capacity to influence the behaviour by the authority.

The legitimate power is in a tight relation with the power to reward or to sanction (the official person may reward or sanction), but differs from it because the legitimacy does not depend on the relations with anothers, but rather on the position from the hierarchy of the authority in the organization.

To exemplify it may take in discussion two cases:

-legitimacy due to the position - from a family, the eldest person;
- legitimacy due to a title of doctor in medicine etc.

The legitimate power which can have persons in a organization increases proportional with the promotion in the hierarchy.

The source of the legitimacy is given by the authority manifested inside and outside of the organization, respectively, the dominant values of the group or of the society, the acceptance of the social structures and, of course, the recognition of a person or of a group having the power, creating the obligation to accept the power and to be influenced.

The social education stays at the basis of the fact that the persons from the organizations have the disponibilities to submit theirself, so, it contributes to the functioning of the legitimate power.

In the frame of the contemporary society, it is ascertained a greater and greater erodation of the traditional legitimacy.

The referential power represents the capacity to influence the behaviour of the people by identification and goes from the attraction of the simpathy of anothers. A such power is based on the identification of the employees with the managers, but the conduction is exerced by using the personal atraction.

Because the atractivity and the charismatic qualities of one person, it is born the desire of another person to identify himself with this one. To exemplify, it may remind the promotion agencies realizing advertising which make appeal to the diverse celebrities from the world of fashion sport, showbiz and anothers.

The way in which is underlined and maintained the referential power depends in a great part on the interpersonal relations which are established, being able to impulse the admiration and the sympathy of others. It is very important the creation and the maintaining of the sympathy because this can influence us in the sense to accept easier diverse opinions and points of view of another persons which gained our sympathy.

The subordinates want to identify theirself with the charismatic chief before to 
take into account the power to award, to sanction or his legitimacy.

In each organization, indifferently of the hierarchical position detained by each member, it may assert the fact that each from them may be admired and sympathised, that makes us to conclude that the legitimate power is more accessible in comparison with all other types of power.

The expertise power is based on a very good knowledge in the activity domain of the manager.

In an organization, the expertise power represents a valuable trump for the managers, because is associated with the efficiency in the work and exists independently with the hierarchical position, but its importance is recognized by implication of the staff from the lower levels in taking decisions at the upper levels of the management. More the charges to be fulfilled are important, more they are complex and more difficult to realize, more the expertise power becomes accessible. The experts are considered as having knowledge and the understanding qualified in well defined domains.

In the organizations, the specialists from the functional compartiments have expertise power in their domains.
The responsability represents the duty to justify the actions or their failures. In function of of the results, each manager will be awarded or sanctioned, after case, having in view the principles and the rules from the organizations, as well as the wage politics of the organization.

But, also, the responsability represents the realization of the charges of the poste in an appropriate way. The resposability has to be understood as a mutual obligation person organization, in the sense that each employee implies in the realization of the objectives of the organization, but the organization, at its turn, invests in the person.

The relation must be mutual profitable, but it may be deteriorated if one of the part does not manifest full interest in exercising the responsability in realising the needs of other part. It may identify responsabilities which derive, on one part, from the realizing the functions of the management, and, on other hand, responsabilities refering to the elaboration, foundation and the transmitting of the decisions.

It may specify, at last, the fact that the power, authority and responsability have to be correlated.

\section{References:}

[1] Turcu, O., et alli, Management, Editura Alma Mater, Bacău, 2008, p.144;

[1] McClelland D., Power: The Inner Experience, Irgvinton Publishers, New York, 1975. Apud Zorlențan, T., Burduş, E., Căprărescu, G., Managementul organizației, Editura Economică, Bucureşti, 1998, p.520;

[2] Bennis, W., Nanus, B., Liderii. Strategii pentru preluarea conducerii, Business Tech International Press, Bucureşti, 2000. 